This is tantamount to declaring that practices expressly permitted by Parliament are unethical.

The clause of the Act which has evoked this difference of opinion is the so-called social clause. This states that an abortion may be carried out when there is a risk to the physical or mental health of any of the existing children of the pregnant woman's family. As with the other clauses, two registered medical practitioners, acting in good faith, must decide that such a risk is greater than that involved in terminating the pregnancy.

The Council of the BMA regards this clause as unacceptable because it embodies the principle of acting on behalf of someone other than the patient herself. Presenting the council's views to the conference, Dr Gibson (see $B M J$, July 6, Supplement, p. 25) said that this principle was "completely at variance with medical tradition. Once that principle was abandoned, the way was opened to the legalization of practices which had been regarded elsewhere as com. pletely reprehensible."

The conference then debated the motion that the association should not oppose "that part of the Abortion Act referring to social grounds". The motion was lost, whereupon Dr G. R. Outwin proposed that "the ethical machinery of the association should not be invoked in respect of any member who may be properly associated with the termination of pregnancy within any of the provisions defined in the Abortion Act 1967". One speaker referred to the "Gilbertian" situation that could arise if doctors who had acted in accordance with the law were exposed to ethical proceedings to justify their behaviour. Another member said that doctors might, as individuals, disagree with the law, but he asked whether they had any inherent right to frustrate the intention of Parliament.

Dr Outwin's motion was also lost. This means that doctors who carry out abortions on the grounds permitted in the social clause are liable to be called before the Central Ethical Committee of the BMA. The committee has the power to recommend expulsion and its recommendations are in effect "rubber-stamped" by the council of the BMA. Dr J. Havard, the secretary of the Ethical Committee, asked to comment on the BMA's position towards the Act, said on the telephone this week that there are many practices which are not illegal, for example adultery, which are nevertheless unethical. In the opinion of his committee, there are practices permitted in the Abortion Act which are also unethical. He added that the logical extension of the principle embodied in the social clause, that the health of people other than the patient should be grounds for treatment, was that aggressive psychopaths should be castrated and euthanasia permitted.

Dr Havard agreed that the discretion given to doctors under the Act was likely to be restricted to some extent by their liability to appear before the Ethical Committee. He pointed out that the social clause had been inserted into the Act at a late stage of the debate in the House of Lords, on the motion of Baroness Summerskill, and that her amendment was not really necessary to deal with the kind of case she described. The House of Lords, Dr Havard said, is a predominantly nonmedical body and it is of course possible that a nonmedical body could be in error when legislating on medical matters. Dr Havard denied that the position adopted by the BMA is in any way contrary to the intentions of Parliament.
No doctor has yet appeared before the Ethical Committee for carrying out legal but unethical abor. tion, and because abortion cases, like other cases, are confidential, it is not clear on what evidence a doctor could be brought before the committee. The usual practice is for a member of the BMA to inform a doctor suspected of unethical practices that he proposes to bring the case to the attention of the Ethical Committee.

\section{Return of the Locusts}

Events have quickly justified the forebodings of the Anti-locust Research Centre, which was still hoping as recently as May this year that it would be possible to contain the swarms of desert locusts then being reported along the coasts of the Red Sea and Arabia by using conventional methods (see Nature, 218, 626; 1968). In the event, control has been inadequate and, according to reports reaching the centre from Saudi Arabia and Jordan, breeding in the Arabian peninsula has been unprecedentedly late and almost unbelievably successful. In Ethiopia and the Sudan, the situation is little better. Large numbers of swarms are breeding in the summer breeding areas.

The situation in the whole area has either become or is becoming out of control; if past experience is any guide, once swarm cycles of plague proportions have become established, they will persist for several years. Saudi Arabia has been facing a serious plague situation and the swarms, which have now begun to migrate into North Africa, will almost inevitably return later in the year, probably on an increased scale. On the other side of the Red Sea, swarms have already migrated from the Somali Republic into northern Ethiopia and it seems that by October and November they will migrate from there to Kenya. As things stand, any control measures other than extensive aerial spraying can be nothing more than local palliatives; even aerial spraying is unlikely to terminate the plague.

Since the end of the last major plague of desert locusts in 1963, the whole breeding area has been virtually free of locusts. Solitary locusts have been reported, but not large swarms. The primary cause of the resurgence, the first sign of which appeared late last year, seems to have been a series of heavy rains in several of the arid areas of Arabia and North Africa in the autumn of 1967 . The luxuriant vegetation provided the locusts with unusually favourable and prolonged breeding conditions. By February and March, when Mr J. Roffey of the Anti-locust Research Centre went to advise the Saudi Arabian Government's locust control officers, there were large bands of locust nymphs or hoppers on the coastal plains of Arabia. Attempts at control were only partially successful and large numbers of locusts escaped inland where they have since bred to plague proportions. In Ethiopia and the Somali Republic, the pattern has been similar although control in late 1967 and early this year was more successful.

The prolonged recession has also probably contributed to the resurgence by inducing a false sense of security and a relaxation of field surveys and control. Roffey's report from Saudi Arabia suggests that the control efforts there were too small and too late to be really effective. There has been no aerial spraying, 


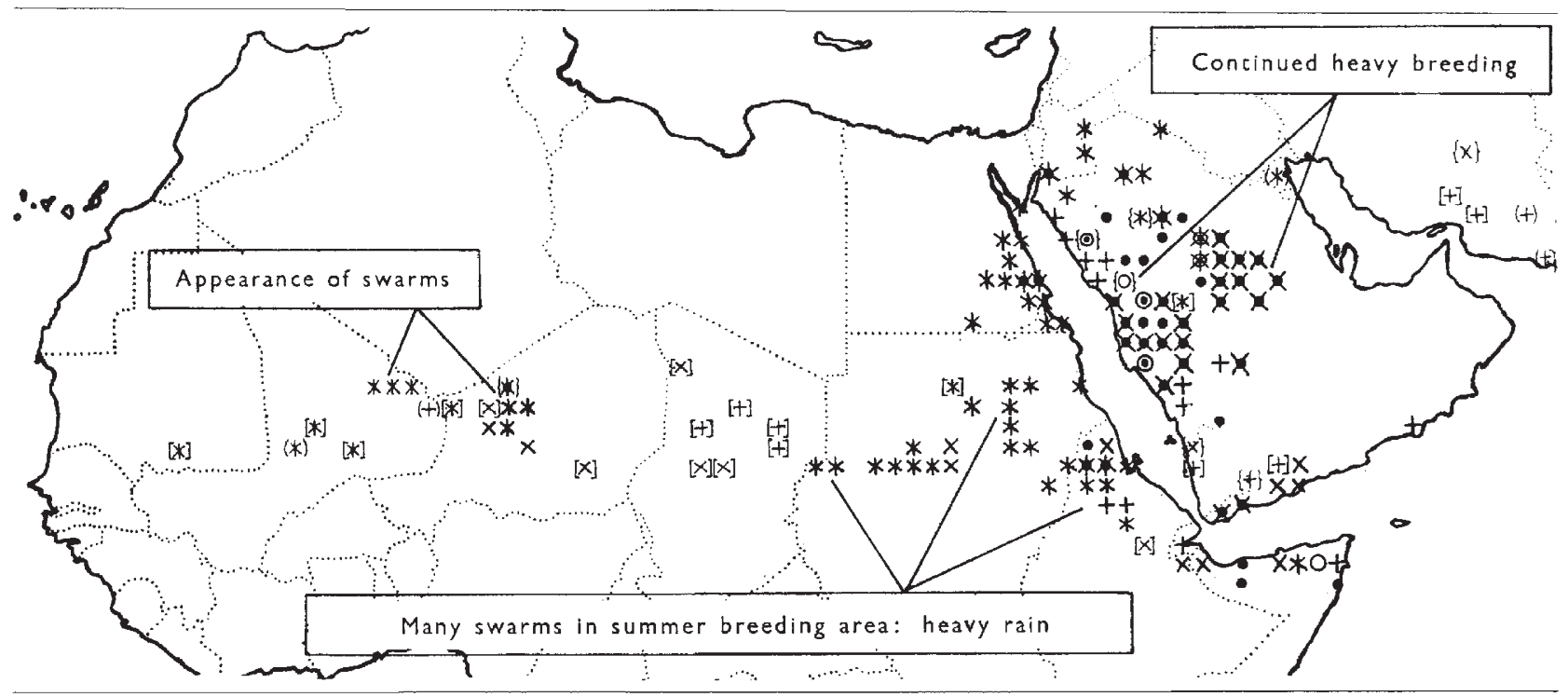

The reported distribution of locusts in Africa and Arabia during June and early July 1968 (from Desert Locust Information Service). Egglaying or eggfields 0 ; hoppers $\bullet$; adults, immature $\times$; adults, mature or partly mature $*$; adults, maturity unknown + .

only killing with bait and, despite help from the Antilocust Research Centre and teams from Pakistan and Egypt, time has now run out and the swarms are beyond control.

Discouraging reports are also coming in from West Africa. Swarms of desert locusts have been sighted in northern Mali and Niger. In 1961, spraying in Moroceo broke the swarm cycle of the desert locust in West Africa and from then until last year swarms were not seen in the area. Last year, swarms were controlled by the former French colonial organization, Organization Commune de Lutte Antiacridienne et de Lutte Antiavian (OCLALAV), but some locusts must have escaped. Although the Information Service had few reports of swarms in Algeria it seems virtually certain that locusts which escaped last year's control, bred in southern Algeria during the winter and have returned in swarms to Mali and Niger. Unless the control now in progress is effective, the desert locust looks like re-establishing its swarm cycle in West Africa.

\section{In Defence of the Ångstrom}

A GRovP which includes most leading spectroscopists issued this week a statement about the adoption of SI units. Their case is that two units banned by the SI system, the Angstrom and the $\mathrm{cm}^{-1}$, are so convenient that they should not be dropped. The full text of the statement is as follows.

"The Inter-Union Commission for Spectroscopy was established by ICSU (International Council of Scientific Unions) in order to ensure full cooperation between spectroscopists in chemistry and astronomy and physics, and possibly other fields. In particular, it was felt that questions of notation should not be decided by any single Union, but only after consultation between all parties within the framework of an Inter-Union Commission.

"Recently the question of the adoption of the SI System of Units (Système Internationale) has been brought to the attention of the members of the commission. While all the members of the commission are strongly in favour of most of the recommendations embodied in the SI system, it is felt that the proposal that the units $\AA$ and $\mathrm{cm}^{-1}$ should be abandoned is most unwise, since they have been used from the beginning of spectroscopy and all the immense literature in the field employs these units (which are metric). The enforcement of such a change could undermine the respect for the SI system as a whole and thus spoil an otherwise good idea. At any rate, after consulting many spectroscopists, the commission has come unanimously to the conclusion that no one should be forced by any journal to abandon the $\AA$ and $\mathrm{cm}^{-\mathbf{1}}$. Most of the members of the commission would go further and recommend the indefinite preservation of these two units in spectroscopy, since both are metric and of a very convenient size.

"The importance of the Angstrom as a unit is, moreover, not confined to spectroscopy. It is a very convenient unit for interatomic distances and chemical bond lengths, and its elimination in this connexion is undesirable."

The statement, issued under the aegis of the InterUnion Commission for Spectroscopy (which represents the International Astronomical Union, the International Union for Pure and Applied Physics and the International Union for Pure and Applied Chemistry), is signed by twelve eminent spectroscopists. They are, for the IAU, A. H. Cook, B. Edlen, J. C. Phillips and M. J. Seaton; for the IUPAP, G. Hertzberg, A. Kastler, M. Migeotte and W. C. Price; and for the IUPAC, V. A. Fassel, R. N. Jones, R. C. Lord and H. W. Thompson. It is probably fair to say that resentment about the demise of the Angstrom unit has been simmering ever since scientists realized that it was to go; but this is the first time that the opposition has received such strong institutional support. Chemists may now be encouraged to set up their own barricades -in defence of the calorie.

\section{Fuel Economy}

BrITATN is about to be the first country with a computerized statistical model of an entire scetor of the national fuel economy, though quitc how it is used 